\title{
Second-degree heart block associated with envenomation by Vipera berus
}

\author{
R. S. MOORE \\ Accident and Emergency Department, Morriston Hospital, Swansea, England
}

\section{SUMMARY}

Evenomation by the common European adder (Vipera berus) is well known for its significant morbidity but low mortality. Cardiac complications tend to take second place to the systemic upset and usually only comprise non-specific ECG changes. This case illustrates many of the classical features of adder bite but it is also the first account of heart block as a complication.

\section{CASE REPORT}

A 69-year-old man, with a history of myocardial infarction 10 years previously; attended the Accident and Emergency Department of Morriston Hospital, Swansea, Wales, 30 min after being bitten on the right thumb by a common adder $(V$. berus $)$. He immediately felt unwell and, on arrival at hospital, he was complaining of abdominal pain and vomiting. Diarrhoea developed within minutes of arrival. On examination, he was shocked (pulse $60 / \mathrm{min}$ with decelerations, blood pressure $80 / 50 \mathrm{mmHg}$ ) and there was some discolouration of the tip of the right thumb at the site of the bite. There was epigastic tenderness and guarding but no other evidence of peritonism. The electrocardiogram showed intermittent $2: 1$ second degree heart block (Fig. 1).

Investigations on arrival: $\mathrm{Hb} 16.5 \mathrm{~g} / \mathrm{dl}$, WCC $16.4 \times 10^{9}$, platelets $497 \times 10^{9}$, serum sodium $140 \mathrm{mmol} / \mathrm{L}$, potassium $4.0 \mathrm{mmol} / \mathrm{L}$, bicarbonate $21 \mathrm{mmol} / \mathrm{L}$, urea $8.0 \mathrm{mmol} /$ L. Blood gas analysis was not performed. He was given polygeline Infusion $500 \mathrm{ml} \mathrm{stat}$ and $600 \mu \mathrm{g}$ atropine intravenously which, together with $10 \mathrm{mg}$ metoclopramide, provided some relief although he remained hypotensive. His right hand was immobilized in a splint.

He received one ampoule of Zagreb antivenom intramuscularly together with further intravenous fluids and his blood pressure improved. Six hours after admission he reverted to sinus rhythm and the gastrointestinal symptoms resolved. Serial ECG and cardiac enzyme studies were all normal. Within $48 \mathrm{~h}$ of admission, a cellulitis had arisen from the site of the bite and had extended to above the elbow. There was also an area of

Correspondence: $\operatorname{Mr}$ R. S. Moore, Registrar in Accident and Emergency, Countess of Chester Hospital, Chester, England. 


\section{DISCUSSION}

Envenomation by $V$. berus has been well described (Persson \& Irestedt, 1981; Reid, $\frac{3}{8}$ 1976, 1985; Theakston \& Reid, 1976) and, although significant morbidity has been ? reported, the mortality is low (Reid, 1976). Early features of poisoning include abdominal pain, vomiting, diarrhoea, shock and swelling of the bitten part. A bleeding tendency is common in viper bites but is rare with adder bite (Reid, 1976). These $\overline{\underline{F}}$ features can persist for up to $36 \mathrm{~h}$ but, by this time, the main problem is usually the site $\frac{\bar{\sigma}}{\bar{\phi}}$ of envenomation, where the swelling can be extensive and tissue necrosis can follow $\varrho$ (Reid, 1976). Laboratory investigations in severe poisoning often show a neutrophil leucocytosis in the acute phase associated with a lowered bicarbonate reflecting a degree $\vec{\bullet}$ of metabolic acidosis (Reid, 1976).

Non-specific ECG changes, such as T-wave inversion, have been reported in all $\stackrel{\vec{\omega}}{\omega}$ degrees of poisoning (Persson \& Irestedt, 1981; Reid, 1976) but this appears to be the $\stackrel{\oplus}{3}$. first report of heart block associated with adder bite. The precise mechanism is $\mathrm{ir}$ uncertain although it recognized that Mobitz Type 2 heart block is usually due to dysfunction in the Bundle of His. The patient had a confirmed history of ischaemic $\vec{\sigma}$ heart disease but had been asymptomatic for the preceding 10 years. Moreover, there 9 was no evidence of myocardial damage on this admission. Atropine needs to be used $\overrightarrow{-}$ with caution in Mobitz Type 2 heart block as it is known that a paradoxical lowering of $\frac{c}{\sigma}$ the ventricular rate can occur with an increased atrial rate due to an unmasking of a $2: 1 \mathrm{\Phi}$ block. Atropine was used in this case to treat episodes of profound bradycardia $\ddot{\circ}_{0}$ associated with hypotension to good effect.

Reid's criteria for the use of antivenom (Reid, 1976) are: persisting hypotension, significant leucocytosis (especially if over $20 \times 10^{9} / \mathrm{L}$ ), evidence of acidosis, ECE changes, raised creatinine phosphokinase levels and, in adults, swelling of the affected limb within $2 \mathrm{~h}$ of the bite. The use of antivenom in this case would appear to have been $\frac{\AA}{\circ}$ justified. The usual method of administration is the intravenous infusion of two $\overrightarrow{\overrightarrow{0}}$ ampoules with full resuscitation facilities available in case of anaphylaxis. The low 3 dosage used in this case was due to inexperience in the use of the antivenom. In light of this, whether or not the improvement in the condition of the patient was due to the antivenom or to rehydration is uncertain. In addition, one wonders if the extent of tissue $\stackrel{\oplus}{3}$ necrosis could have been reduced.

\section{REFERENCES}

Persson H. \& Irestedt B. (1981) A study of 136 cases of adder bite treated in Swedish hospitals during one year. Acta Medica Scandinavica 210, 433-9.

Reid H. A. (1976) Adder bites in Britain. British Medical fournal 2, 153-6.

Reid H. A. (1985) Poisoning due to snake bite. In: Concise Guide to the Management of Poisoning, 3rd edn, Vale J. A. \& Meredith T. J. (eds), pp. 180-91. Chuchill Livingstone, Edinburgh.

Theakston R D. G. \& Reid H. A. (1976) Effectiveness of Zagreb antivenom against the adder, Vipera berus. Lancet ii, 121-3. 